\title{
The Asian Citrus Psyllid Host Murraya koenigii Is Immune to Citrus Huanglongbing Pathogen 'Candidatus Liberibacter asiaticus'
}

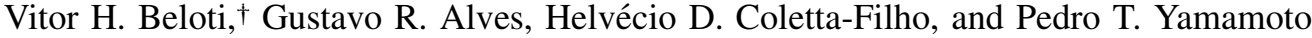

First, second, and fourth authors: Department of Entomology and Acarology, 'Luiz de Queiroz' College of Agriculture, University of São Paulo, C.P. 9, Piracicaba, SP, 13.418-900, Brazil; and third author: Centro de Citricultura Sylvio Moreira, IAC, C.P. 4, Cordeirópolis, SP, 13490970, Brazil.

Accepted for publication 10 April 2018.

\begin{abstract}
The Asian citrus psyllid (ACP) Diaphorina citri, vector of 'Candidatus Liberibacter asiaticus' (CLas), the putative causal agent of citrus Huanglongbing (HLB), is controlled by application of insecticides, which, although effective, has resulted in serious biological imbalances. New management tools are needed, and the technique known as "trap crop" has been attracting attention. A potential plant for use as a trap crop in the management of the ACP is Murraya koenigii (curry leaf). However, for this plant to be used in the field, it needs to be attractive for the vector and must not harbor CLas. To verify the potential of curry leaf as trap crop for the management of HLB, we investigated the ability of $D$. citri to transmit CLas

to $M$. koenigii, and to other test plants, including M. paniculata (orange jasmine) and cultivar Valencia sweet-orange seedlings. For the tests, the insects were reared on a symptomatic CLas-infected plant and allowed to feed on the three test plant species. The overall maximum transmission rate for the citrus seedlings was $83.3 \%$, and for orange jasmine was $33.3 \%$. Successful transmission of CLas by ACP to the curry-leaf seedlings was not observed, and it was treated as immune to CLas. Supported by the previous results that $M$. koenigii is attractive for ACP, these results indicate that curry leaf is an excellent candidate for use as a trap crop, to improve the management of the insect vector and consequently of HLB.
\end{abstract}

Huanglongbing (HLB) disease is considered to be the most serious biological problem affecting citrus (Bové 2006; Gottwald 2010). HLB is associated with a Gram-negative $\alpha$-proteobacterium that is restricted to phloem and not culturable, the bacteria 'Candidatus Liberibacter' spp. (Bové 2006; Jagoueix et al. 1994; Gottwald 2010). Among the proteobacteria, 'Candidatus Liberibacter asiaticus' (CLas) is the predominant species and has caused enormous economic losses around the world, making citrus growing unfeasible in many countries (Bové 2006; Gottwald 2010). In Asia and the Americas, the bacterium is transmitted by the Asian citrus psyllid, Diaphorina citri Kuwayama (Hemiptera: Liviidae) (Bové 2006; Gottwald 2010; Wang and Trivedi 2013).

In view of the lack of a cure for HLB (Bové 2006), palliative and preventive measures are employed for its management, including control of the insect vector and eradication of symptomatic plants, as well as the use of healthy seedlings for new plantations (Belasque and Bassanezi 2010; Hall et al. 2013).

However, management of HLB using exclusively insecticides to minimize the psyllid population is economically and environmentally unsustainable for the citrus industry (Kruse et al. 2017). Insecticides, as currently used, are not sufficient to prevent the spread of CLas (Kruse et al. 2017), requiring frequent spraying on the citrus plants and altering the balance between pests and their natural enemies, causing secondary pest outbreaks, pest resurgence and selection of resistant populations (Guedes and Cutler 2013; Tiwari et al. 2011; Yamamoto and Bassanezi 2003; Yamamoto et al. 2014). Therefore, new management tactics must be developed in order to reduce the damage and losses caused by the disease.

${ }^{\dagger}$ Corresponding author: V. H. Beloti; E-mail: vitorbeloti@usp.br

Funding: This study was supported by Fundação de Amparo à Pesquisa do Estado de São Paulo (FAPESP) grant 2013/25157-0.

*The $\boldsymbol{e}$-Xtra logo stands for "electronic extra" and indicates that one supplementary figure is published online.

(C) 2018 The American Phytopathological Society
The cultural/behavioral control tactic known as a trap crop has attracted attention (Yan et al. 2015). A trap crop can be defined as "plants grown to attract insects or other organisms to protect the major crops from pest attacks, preventing pests from attacking the crop or concentrating them in a certain part of the field where they can be economically destroyed" (Shelton and Badenes-Perez 2006).

A species for potential use as a trap crop to manage $D$. citri is the curry leaf (Murraya koenigii L.). This plant, besides being a good host for the insect (Teck et al. 2011; Westbrook et al. 2011), in trials under controlled conditions proved to be more attractive to the vector than the citrus plants (Beloti et al. 2017). Damsteegt et al. (2010) were not able to determine whether curry leaf could be a host of CLas, suggesting the need for more-detailed experiments before $M$. koenigii could be recommended as a trap crop in the field to improve the management of HLB.

This study evaluated whether curry leaf is a host of the bacterium CLas, comparing it with orange jasmine (Murraya paniculata) and with citrus (Citrus sinensis), in inoculation tests performed with the insect vector $D$. citri.

\section{MATERIALS AND METHODS}

Insects and plants. D. citri were reared in cages $(45 \times 45 \times$ $50 \mathrm{~cm}$ ) containing orange-jasmine plants (M. paniculata), considered to be one of the most suitable host species for this insect's development (Alves et al. 2014; Nava et al. 2007). The rearing colony was maintained in a climate-controlled room $\left(25 \pm 2^{\circ} \mathrm{C}, 60 \pm\right.$ $10 \% \mathrm{RH}$, and $14 \mathrm{~h}$ light/10 $\mathrm{h}$ dark photoperiod), following a method proposed by Parra et al. (2016). The insects were frequently submitted to qPCR (real-time quantitative PCR) tests to confirm that no specimens in the colony were infected with CLas.

HLB-symptomatic orange plants (Citrus sinensis (L.) Osbeck 'Pêra') grafted on cultivar Rangpur lime (C. limonia Osbeck), at 1 to 2 years of age were used in the bioassays as source plants of CLas. The presence of the bacterium in these plants and specifically in the branches where the insects were confined was confirmed by qPCR 
before the acquisition access period (AAP) by the psyllid $D$. citri. These plants were kept under greenhouse conditions favorable for the development of the bacterium, due to their natural intolerance of high temperatures (Lopes et al. 2009, 2017).

The test plants used in the experiment were curry leaf (Murraya koenigii), orange jasmine (M. paniculata), and sweet orange (C. sinensis 'Valencia') grafted on citrumelo Swingle (C. paradise Macf. $\times$ Poncirus trifoliata L. (Raf.)). The age of experimental plants was approximately 8 months old, and were kept in a greenhouse and previously submitted to qPCR tests to confirm that they were free of the bacterium CLas.

Transmission of CLas by $D$. citri to the test plants. Adults of $D$. citri from the rearing colony and free of CLas were confined for seven days in mesh bags on branches of the CLas-source plants containing new shoots 10 to $15 \mathrm{~mm}$ long, for oviposition. After this period, the adult psyllids were removed and discarded, and the eggs left on the source plants to allow the nymphs to hatch and develop to the adult phase, when the AAP was fulfilled. This strategy has resulted in the greatest success in CLas acquisition and transmission by $D$. citri under controlled conditions (Inoue et al. 2009; PelzStelinski et al. 2010), as well as providing the necessary latency period (Canale et al. 2017).

After the insects emerged, groups of approximately 10 individuals were transferred with an aspirator to branches containing new shoots on curry leaf, orange jasmine and citrus test plants for a 10-day inoculation access period (IAP). Both the acquisition and the inoculation were conducted in a climate-controlled room at $25 \pm$ $2^{\circ} \mathrm{C}$ and $14 \mathrm{~h}$ light $/ 10 \mathrm{~h}$ dark photoperiod.

After the IAP, the insects used in the bioassay were removed from the plants, killed by freezing, stored in 2.0-ml Eppendorf tubes containing $70 \%$ ethanol, stored in a freezer at $-20^{\circ} \mathrm{C}$ and tested individually for the presence of CLas, through qPCR.

The test plants were kept in a greenhouse for 24 months. They were analyzed approximately every 6 months for the presence of CLas, through qPCR. The transmission rate was estimated as the number of qPCR-positive plants divided by the total number of plants tested.

The experiment was repeated in three different periods: experiment 1, beginning of spring (September 2014); experiment 2, end of summer (March 2015); and experiment 3, end of spring (November 2015). In experiment 1, a total of 10 plants were used for each treatment. In the second experiment, 6 citrus, 10 orangejasmine, and 10 curry-leaf plants were used. In the third experiment, 12 citrus, 12 orange-jasmine, and 14 curry-leaf plants were used.

DNA extraction from insects and plants. DNA was extracted from the psyllids individually, according to the method described by Coletta-Filho et al. (2014). Each insect was macerated using the TissueLyser II system (Qiagen, Valencia, CA) at $25 \mathrm{~Hz}$ for $60 \mathrm{~s}$ in a 2.0-ml microtube containing $100 \mu \mathrm{l}$ of STE buffer (10 mM Tris$\mathrm{HCl}, 1 \mathrm{mM}$ EDTA, and $25 \mathrm{mM} \mathrm{NaCl}$ ) and two 3-mm beads. After addition of $15 \mu \mathrm{l}$ of Proteinase K $(200 \mu \mathrm{g} / \mathrm{ml})$, the samples were incubated at $56^{\circ} \mathrm{C}$ for $30 \mathrm{~min}$. Total DNA was purified using the Wizard Genomic DNA Purification Kit (Promega Corporation, Madison, WI), following the manufacturer's instructions. The final pellet was eluted in a final volume of $50 \mu$ l of elution buffer $(10 \mathrm{mM}$ Tris, $1 \mathrm{mM}$ EDTA, and $20 \mu \mathrm{g}^{-1} \mathrm{RNAse}$ ) and stored at $-20^{\circ} \mathrm{C}$ prior to the qPCR tests.

Total DNA from the plants was extracted using the cetyltrimethylammonium bromide (CTAB) method adapted from Murray and Thompson (1980). Leaves of branches where the insects fed were collected, and the petiole and vein were used for DNA extraction. Briefly, the petiole and central vein were cut into small pieces with a scalpel and $200 \mathrm{mg}$ of tissue was used for DNA extraction. For the samples of $C$. sinensis and $M$. paniculata, the plant tissues were activated in $2 \mathrm{ml}$ plastic tubes containing $5-\mathrm{mm}$ beads and $625 \mu \mathrm{l}$ of buffer 1 (100 mM Tris [pH 8.0], $50 \mathrm{mM}$ EDTA, and $500 \mathrm{mM} \mathrm{NaCl}$ ). The plant tissue was disrupted using a TissueLyser II system homogenizer at $30 \mathrm{~Hz}$ for $120 \mathrm{~s}$; then, $725 \mu \mathrm{l}$ of buffer $2(5 \% \mathrm{CTAB}$,
$10 \%$ Sarcosyl and $10 \mathrm{mM}$ B-mercaptoethanol) was added to the tube. This was held at $65^{\circ} \mathrm{C}$ for $30 \mathrm{~min}$ and then centrifuged for $5 \mathrm{~min}$ at 3,500 rpm. The supernatant was transferred to a new $1.5-\mathrm{ml}$ microtube, followed by extraction with chloroform/isoamyl alcohol 24:1 and precipitation with isopropanol, and the total DNA was suspended in $400 \mu \mathrm{l}$ of 1/10TE + RNase. Tissues of $M$. koenigii were triturated in 2 ml-plastic tubes previously cooled with liquid $\mathrm{N}$ to minimize oxidation, following by the addiction of buffers 1 and 2 together in the plastic tube, after which the DNA extraction was started as above describe.

qPCR. The presence of CLas in the plant and psyllid samples was determined by qPCR, using primers and probe developed by Lin et al. (2010), with the probe label with FAM/Iowa Black FQ (IDT Inc., Coralville, IA). All amplifications were performed in duplicate, using the ABI 7500 Fast thermal cycler (Life Technology Corporation, Carlsbad, CA) using the default for the cycling conditions $\left(2 \mathrm{~min}\right.$ at $50^{\circ} \mathrm{C}$ and $10 \mathrm{~min}$ at $95^{\circ} \mathrm{C}$ followed by 40 cycles of amplification of $15 \mathrm{~s}$ at $95^{\circ} \mathrm{C}$ and $1 \mathrm{~min}$ at $60^{\circ} \mathrm{C}$ ). The amplifications were conducted in a total volume of $13 \mu$ l containing $3 \mu \mathrm{l}$ of total DNA ( $\approx 150 \mathrm{ng}), 10 \mu \mathrm{M}$ of each primer, $5 \mu \mathrm{M}$ of the probe and $2.6 \mu$ l of $5 \times$ HOT FIREPol Probe qPCR Mix Plus (ROX) (Solis Biodyne, Tartu, Estonia). The PCR efficiency was monitored by using, in all runs, three different known amounts of cloned plasmids containing the extended CLas elongation factor insert, as well as DNA samples from tissue known to be CLas-infected. As the negative control, tissues of healthy plants were used, and Milli-Q autoclaved water as the mock sample. Only samples with $C_{T}$ values lower than 36.0 were considered positive for the presence of CLas (Ammar et al. 2011; Canale et al. 2017; Coletta-Filho et al. 2014; Hilf 2011).

\section{RESULTS}

Source plants. The experiments were repeated in three different periods, using the same methods in each period. The branches used for the acquisition of CLas by the vector $D$. citri were just beginning to develop, and therefore without leaves showing symptoms of HLB, but CLas positive. In the first experiment, eight CLas-positive source plants were used, and the branches used in the acquisition of the bacterium by the psyllids showed $\mathrm{C}_{\mathrm{T}}$ values between 20.66 and 25.89 (mean $22.43 \pm 0.61$ ) (Table 1).

In the second and third experiments, 14 other CLas-positive source plants were used, and all the branches used to feed the vector for bacterial acquisition were infected, with $\mathrm{C}_{\mathrm{T}}$ values ranging from 18.08 to 31.73 (mean $21.89 \pm 1.05$ ) (Table 1 ).

Infectivity rate of the psyllids after the AAP. The percentage of psyllids that acquired CLas from the source plants varied significantly among the experiments, ranging from 20.2 to $69.0 \%$. The concentration of CLas in these positive insects was also variable. Although these indices were variable, which is inherent to the biology of the system under study, the great majority of the test plants of all three species and in all three experiments contained CLas-positive insects (Table 2). A total of 25 of the 28 citrus test plants in the three experiments contained at least one positive insect. These numbers were even higher for the test plants orange jasmine ( 31 of 32 plants) and curry leaf (33 of 34), thus providing a large number of plants that received CLas-infected psyllids.

CLas transmission to test plants after the IAP. As noted in the acquisition, the efficiency of CLas transmission to the same testplant species $(C$. sinensis and $M$. paniculata) varied among the experiments; the third experiment showed the lowest efficiency of transmission. In general, citrus was much more susceptible to CLas infection (maximum efficiency of $83.3 \%$ ) compared with orange jasmine, with a maximum efficiency of only $33.3 \%$ (Tables 3 and 4 ). In all three experiments, $D$. citri was not able to transmit CLas to $M$. koenigii, in a total of 34 challenged plants, showing that M. koenigii is immune to CLas (Van der Waerden One-Way, $x^{2}=$ 14.03, $P<0.005)$. For the susceptible hosts, there was a direct 
relationship between the number of positive plants and the length of the incubation period. For $C$. sinensis the significance fit of the equation $\left(R^{2}=0.6239 ; y=2.1276 x+6.8112\right)$ was much more significant than for $M$. paniculata $\left(R^{2}=0.3718 ; y=-3.352 x^{2}+\right.$ $11.903 x+7.4796)$. The trend was the same for the CLas concentration and the incubation period for these species, although the $\mathrm{C}_{\mathrm{T}}$ values obtained for CLas in $C$. sinensis in experiment 1 remained constant throughout the 24 months of evaluation. Comparison of the transmission rate and the CLas concentration (inferred by the $C_{T}$ values) showed the greater susceptibility of $C$. sinensis compared with $M$. paniculata. Overall results from three experiments showed the highest $\mathrm{C}_{\mathrm{T}}$ values (low CLas concentration) for the orange jasmine plants which were significantly different of obtained from citrus, with exception for the results from experiment 1 at 18 and 24 months (Tables 3, 4, and 5).

In addition to the high transmission rate of the bacterium to citrus plants, 13 of the 28 CLas-positive plants showed characteristic HLB symptoms; seven of these were obtained in the first experiment, five in the second, and only one plant with symptoms was obtained in the third experiment (Supplementary Fig. S1). These symptoms, most predominantly asymmetric mottling, began to appear within 10 months after the end of the IAP. However, unlike the citrus plants, no orange jasmine expressed symptoms that could be associated with the disease.

TABLE 1. Cycle threshold $\left(\mathrm{C}_{\mathrm{T}}\right)$ values obtained from leaves collected from branches of the source plants of 'Candidatus Liberibacter asiaticus' (CLas) used in the bioassays

\begin{tabular}{lcc}
\hline & \multicolumn{2}{c}{$\mathrm{C}_{\mathrm{T}}$ value } \\
\cline { 2 - 3 } Source plants & Experiment 1 & Experiments 2 and $3^{\mathrm{a}}$ \\
\hline 1 & 22.56 & 22.66 \\
2 & 22.56 & 21.62 \\
3 & 25.89 & 18.95 \\
4 & 20.66 & 19.02 \\
5 & 24.35 & 21.68 \\
6 & 20.92 & 18.75 \\
7 & 21.45 & 18.26 \\
8 & 21.01 & 18.24 \\
9 & - & 27.30 \\
10 & - & 26.68 \\
11 & - & 31.73 \\
12 & - & 21.96 \\
13 & - & 18.08 \\
14 & - & 21.58 \\
Mean & $22.43 \pm 0.61$ & $21.89 \pm 1.05$ \\
\hline
\end{tabular}

${ }^{a}$ In experiments 2 and 3, the same 14 branches were used for CLas acquisition.
As for the citrus plants, the infection rate of the orange-jasmine plants from the third experiment was low, only $8.3 \%$ qPCR-positive (Table 4).

\section{DISCUSSION}

As previously reported, the probability of CLas acquisition by nymphs reared on CLas-infected plants is higher than for specimens that feed on infected plants only during adulthood (Ammar et al. 2016; Pelz-Stelinski et al. 2010). Moreover, as observed in several studies, when the bacterium is acquired in the nymphal stage of the vector, the emerged adults are much more efficient in transmitting CLas to the host plants, having already elapsed the latency period (Ammar et al. 2016; Canale et al. 2017; GraftonCardwell et al. 2013; Inoue et al. 2009; Pelz-Stelinski et al. 2010; $\mathrm{Xu}$ et al. 1988). In order to obtain the maximum efficiency of CLas acquisition by the vector, as well as the transmission of the pathogen to the test plants, the entire development cycle (egg-adult) of $D$. citri used in the present experiments was carried out on CLas-infected citrus plants (CLas-source plants). From these, shortly after emerging to the adult stage, the psyllids were transferred to test plants in order to transmit CLas.

In addition, we used source plants with new shoots, which are preferred by nymphs and adults (Sétamou and Bartels 2015). In spite of this attempt to normalize the experimental conditions, the variations observed among experiments 1,2 , and 3 may be due to the different periods in which the experiments were carried out, mainly regarding temperature variations (Lopes et al. 2017), as well as the physiology and the concentrations of CLas in the source plants (Table 1). The concentration of the bacterium is directly related to the efficiency of its acquisition (Coletta-Filho et al. 2014), and therefore high temperatures contribute to the decrease of the bacterial titer in the plant as well as to the efficiency of acquisition and transmission (Lopes et al. 2013). Although there were variations among the experiments, the efficiency of CLas acquisition ranged between 20 and $70 \%$ (Table 2), within the range reported in the literature when the pathogen was acquired during the nymphal phase of the vector (Ammar et al. 2016; Inoue et al. 2009; Pelz-Stelinski et al. 2010). Another factor affecting the differences in acquisition efficiency between these experiments presented here and those previously published, are the different populations of D. citri present in Brazil and in the United States (Boykin et al. 2012).

CLas transmission rates over $80 \%$ were obtained when sweetorange seedlings were used as test plants (Table 3), and a total of 13

TABLE 2. Adults of Diaphorina citri infected with the bacterium 'Candidatus Liberibacter asiaticus' (CLas) after the acquisition access period, and total number of test plants that received populations of infective psyllids

\begin{tabular}{|c|c|c|c|c|c|}
\hline Test plants & Experiments $^{\mathrm{a}}$ & $\mathrm{qPCR}+/$ total $^{\mathrm{b}}$ & CLas qPCR+ $(\%)^{\mathrm{c}}$ & Cycle threshold variation & $\begin{array}{l}\text { Plants with } D \text {. citri } \\
\text { qPCR+/total }\end{array}$ \\
\hline \multirow[t]{2}{*}{ Citrus } & 1 & 20/99 & 20.2 & $25.93-35.91$ & $9 / 10$ \\
\hline & 2 & $18 / 51$ & 35.3 & $20.85-34.06$ & $6 / 6$ \\
\hline Overall & & $90 / 268$ & & & $25 / 28$ \\
\hline Mean & & & $33.19 \pm 5.69$ & $21.70( \pm 1.83)-35.13( \pm 0.45)$ & \\
\hline \multirow[t]{2}{*}{ Orange jasmine } & 1 & $35 / 93$ & 37.7 & $23.99-35.85$ & $9 / 10$ \\
\hline & 2 & $58 / 84$ & 69.0 & $18.16-34.25$ & $10 / 10$ \\
\hline Mean & & & $54.57 \pm 7.47$ & $19.94( \pm 1.66)-35.09( \pm 0.38)$ & \\
\hline \multirow[t]{3}{*}{ Curry } & 1 & $33 / 98$ & 33.7 & $22.82-35.43$ & $10 / 10$ \\
\hline & 2 & $26 / 74$ & 35.1 & $20.20-33.94$ & $10 / 10$ \\
\hline & 3 & $95 / 141$ & 67.4 & $18.83-35.68$ & $13 / 14$ \\
\hline Overall & & $154 / 313$ & & & $33 / 34$ \\
\hline Mean & & & $45.39 \pm 8.98$ & $20.62( \pm 0.96)-35.02( \pm 0.44)$ & \\
\hline
\end{tabular}

a Three experiments conducted independently at three different times (described in Materials and Methods).

b Number of $D$. citri adults qPCR-positive for CLas in relation to the total number tested.

c Percentage of $D$. citri adults qPCR+ for CLas.

d Total plants that received $D$. citri qPCR+ in relation to the total plants used in the experiment. 
plants with the characteristic HLB mottling symptoms (Bové 2006) were also present. Transmission rates were much lower for orange jasmine, M. paniculata $(<33.3 \%)$ (Table 4$)$, and transmission did not occur in any of the experiments when $M$. koenigii (curry leaf) test plants were used (Table 6). In contrast to sweet-orange plants, no HLB-associated symptoms were observed in any orangejasmine plants, nor, obviously, in the curry-leaf plants. In addition to the citrus plants, ornamental species of Rutaceae such as M. paniculata and M. koenigii are excellent hosts for D. citri (Alves et al. 2014; Aubert 1987; Teck et al. 2011; Westbrook et al. 2011). Given the wide use of these species as ornamental plants, often next to commercial citrus plantations (Halbert and Manjunath 2004; Hung et al. 2000; Sétamou et al. 2016), the role of these plants as potential hosts or reservoirs of the HLB pathogen (Damsteegt et al. 2010; Hung et al. 2000) and their role in the epidemiology of HLB (Chakraborty et al. 1976; Halbert and Manjunath 2004) have attracted attention.

In agreement with the results of previous studies, although M. paniculata is an alternative reservoir for CLas (Table 4), in general the concentration of this bacterium in infected plants was significantly lower compared with that in citrus (Table 5) (Damsteegt et al. 2010; Lopes et al. 2010; Walter et al. 2012). Similarly, the symptoms in $M$. paniculata infected with CLas were not clearly observed in the present experiments, and in previous reported studies (Damsteegt et al. 2010; Hung et al. 2000; Koizumi et al. 1996; Lopes et al. 2010). However, CLas transmission from M. paniculata to C. sinensis through D. citri (Damsteegt et al. 2010) and from Cuscuta sp. (Zhou et al. 2007) was successful, indicating that orange jasmine can serve as an active reservoir for CLas.

In contrast to $C$. sinensis and $M$. paniculata, which harbor both the vector (D. citri) and the pathogen (CLas), M. koenigii (curry leaf) proved to be immune to the CLas bacterium in all three experiments (Table 6). These results concord with previous observations

TABLE 3. Transmission of the bacterium 'Candidatus Liberibacter asiaticus' (CLas) by the psyllid Diaphorina citri for citrus seedlings (Citrus sinensis), in the three experiments and over time (MAI = months after inoculation)

\begin{tabular}{lcccc}
\hline Experiment & MAI & qPCR+/total $^{\mathrm{a}}$ & CLas $(\%)^{\mathrm{b}}$ & Cycle threshold variation \\
\hline 1 & 10 & $4 / 10$ & 40.0 & $30.58-32.06$ \\
& 18 & $4 / 10$ & 40.0 & $30.59-32.06$ \\
2 & 24 & $8 / 10$ & 80.0 & $30.33-34.44$ \\
& 5 & $1 / 6$ & 16.7 & 31.52 \\
3 & 12 & $3 / 6$ & 50.0 & $16.49-18.54$ \\
& 18 & $5 / 6$ & 83.3 & $17.01-30.73$ \\
& 6 & $1 / 12$ & 8.3 & 19.29 \\
& 12 & $1 / 12$ & 8.3 & 18.21 \\
& 18 & $2 / 12$ & 16.7 & $15.56-33.23$ \\
\hline
\end{tabular}

a Number of qPCR-positive plants for CLas in relation to the total number tested.

b Percentage of plants with the bacterium.

TABLE 4. Transmission of the bacterium 'Candidatus Liberibacter asiaticus' (CLas) by the psyllid Diaphorina citri to orange-jasmine plants (Murraya paniculata), in the three experiments and over time (MAI = months after inoculation)

\begin{tabular}{lcccc}
\hline Experiment & MAI & qPCR+/tota $^{\mathrm{a}}$ & ${\text { CLas }(\%)^{\mathrm{b}}}^{\mathrm{C}}$ & Cycle threshold variation \\
\hline 1 & 10 & $1 / 7$ & 14.3 & 34.10 \\
& 18 & $2 / 6$ & 33.3 & $30.51-32.67$ \\
2 & 24 & $2 / 6$ & 33.3 & $26.74-29.30$ \\
& 5 & $0 / 9$ & 0.0 & - \\
3 & 12 & $0 / 9$ & 0.0 & - \\
& 18 & $3 / 9$ & 33.3 & $31.57-33.61$ \\
& 6 & $3 / 12$ & 25.0 & $30.78-33.41$ \\
& 12 & $2 / 12$ & 16.6 & $29.32-32.78$ \\
& 18 & $2 / 12$ & 16.6 & $28.54-31.59$ \\
\hline
\end{tabular}

a Number of qPCR-positive plants for CLas in relation to the total number tested.

b Percentage of plants with the bacterium. of an absence of symptoms in curry-leaf plants visited by highly infective psyllid populations (Hung et al. 2000; Koizumi et al. 1996), and also the absence of a PCR-positive diagnosis for CLas (Damsteegt et al. 2010; Ramadugu et al. 2016). Killiny (2016) suggested that the nondevelopment of the CLas bacterium in curryleaf plants might be explained by the lower amounts of amino acids, organic acids, sugars and total metabolites in the phloem sap of curry leaf than in orange jasmine and citrus plants, and the larger amount of tartaric acid, which may be a limiting factor for the growth of CLas.

Another explanation is that the curry leaf contains many compounds with antimicrobial and antifungal activity, such as murrayanine, girinimbine, and mahanimbine, and these compounds may limit the development of the bacterium in this plant (Jain et al. 2012). Supporting this hypothesis, Albrecht and Bowman (2012) proposed that the tolerance of Poncirus trifoliata (L.) to HLB might be due to the antimicrobial compounds present in this rootstock.

Similarly to curry leaf, other plant species appear to be completely immune to ' $\mathrm{Ca}$. Liberibacter' sp., despite serving as hosts for psyllids. For example, sweet potato plants (Ipomoea batatas) serving as host for several months for a population of the potato psyllid Bactericera cockerelli (Hemiptera: Psyllidae) infected with the bacterium ' $\mathrm{Ca}$. L. solanacearum' did not become infective (Sengoda et al. 2013). This may result from either a rapid and effective defense response of the plant, or the lack of some specific interaction or compound required by the bacteria, or a combination of both.

Even though curry leaf is not a host of the CLas bacterium, this plant is a good host for the insect vector (Teck et al. 2011; Westbrook et al. 2011) and is preferred by $D$. citri over citrus plants

TABLE 5. Comparison of cycle threshold $\left(\mathrm{C}_{\mathrm{T}}\right)$ values for 'Candidatus Liberibacter asiaticus' in citrus (Citrus sinensis) and orange jasmine plants (Murraya paniculata), in the three experiments

\begin{tabular}{lccc}
\hline Experiments/hosts & \multicolumn{3}{c}{ Months after inoculation } \\
\hline Experiment 1 & 10 & 18 & 24 \\
$\quad$ Citrus & $31.06(0.25)^{\mathrm{a}}$ & $31.88(0.34)$ & $31.72(0.58)$ \\
Orange jasmine & $34.10(0.01)$ & $31.60(0.88)$ & $28.02(0.37)$ \\
$t$ test & 0.0002 & 0.3548 & 0.0081 \\
Experiment 2 & 5 & 12 & 18 \\
Citrus & $31.52(0.25)$ & $23.63(2.20)$ & $22.68(2.09)$ \\
Orange jasmine & $40(0.00)^{\mathrm{b}}$ & $40(0.00)$ & $32.29(0.45)$ \\
$t$ test & 0.0001 & 0.0001 & 0.001 \\
Experiment 3 & 6 & 12 & 18 \\
Citrus & $19.29(0.33)$ & $18.32(0.02)$ & $24.40(5.01)$ \\
Orange jasmine & $32.25(0.51)$ & $31.06(1.00)$ & $30.07(0.89)$ \\
$t$ test & 0.0001 & 0.0001 & 0.0001 \\
\hline
\end{tabular}

a Number in brackets is the standard error among the $C_{T}$ values obtained for the plants.

b The number 40 was used for the undetermined result of qPCR, which means no bacteria amplification.

TABLE 6. Transmission of the bacterium 'Candidatus Liberibacter asiaticus' (CLas) by the psyllid Diaphorina citri to curry-leaf plants (Murraya koenigii), in the three experiments and over time (MAI = months after inoculation)

\begin{tabular}{lrccc}
\hline Experiment & MAI & qPCR+/total $^{\mathrm{a}}$ & ${\text { CLas }(\%)^{\mathrm{b}}}$ & $\mathrm{C}_{\mathrm{T}}$ variation \\
\hline 1 & 10 & $0 / 10$ & 0 & - \\
& 18 & $0 / 10$ & 0 & - \\
2 & 24 & $0 / 10$ & 0 & - \\
& 5 & $0 / 10$ & 0 & - \\
& 12 & $0 / 10$ & 0 & - \\
3 & 18 & $0 / 10$ & 0 & - \\
& 6 & $0 / 14$ & 0 & - \\
& 12 & $0 / 14$ & 0 & - \\
\hline
\end{tabular}

a Number of qPCR-positive plants for CLas in relation to the total number tested.

b Percentage of plants with the bacterium. 
in olfactometer and free-choice tests (Beloti et al. 2017). These characteristics make $M$. koenigii an excellent candidate plant for use as a trap crop in commercial citrus orchards. Studies are in progress to determine the curative potential of $M$. koenigii for CLas in previously infected psyllids, opening prospects for the use of this plant as an antagonistic tool for CLas.

\section{ACKNOWLEDGMENTS}

We thank M. C. S. S. Gil for technical assistance with the qPCR analyses, M. L. Haddad for helping with the statistical analyzes, H. A. S. Pimpinato for assistance during the bioassays, and J. W. Reid for revising the English text.

\section{LITERATURE CITED}

Albrecht, U., and Bowman, K. D. 2012. Tolerance of trifoliate citrus rootstock hybrids to Candidatus Liberibacter asiaticus. Sci. Hortic. (Amsterdam) 147: $71-80$.

Alves, G. R., Diniz, A. J. F., and Parra, J. R. P. 2014. Biology of the huanglongbing vector, Diaphorina citri (Hemiptera: Liviidae) on different host plants. J. Econ. Entomol. 107:691-696.

Ammar, E.-D., Ramos, J. E., and Hall, D. G. 2016. Acquisition, replication and inoculation of Candidatus Liberibacter asiaticus following various acquisition periods on huanglongbing-infected citrus by nymphs and adults of the Asian citrus psyllid. PLoS One 11:e0159594.

Ammar, E.-D., Shatters, R. G., Jr., Lynch, C., and Hall, D. G. 2011. Detection and relative titer of 'Candidatus Liberibacter asiaticus' in the salivary glands and alimentary canal of Diaphorina citri (Hemiptera: Psyllidae) vector of citrus huanglongbing disease. Ann. Entomol. Soc. Am. 104: 526-533.

Aubert, B. 1987. Trioza erytreae Del Guercio and Diaphorina citri Kuwayama (Homoptera: Psyllidae), the two vectors of citrus greening disease: Biological aspects and possible control strategies. Fruits 42:149-162.

Belasque, J., Jr., and Bassanezi, R. B. 2010. Lessons from huanglongbing management in São Paulo state, Brazil. J. Plant Pathol. 92:285-302.

Beloti, V. H., Santos, F., Alves, G. R., Bento, J. M. S., and Yamamoto, P. T. 2017. Curry leaf smells better than citrus to females of Diaphorina citri (Hemiptera: Liviidae). Arthropod-Plant Interact. 11:709-716.

Bové, J. M. 2006. Huanglongbing: A destructive, newly-emerging, century-old disease of citrus. J. Plant Pathol. 88:7-37.

Boykin, L. M., De Barro, P., Hall, D. G., Hunter, W. B., McKenzie, C. L., Powell, C. A., and Shatters, R. G., Jr. 2012. Overview of worldwide diversity of Diaphorina citri Kuwayama mitochondrial cytochrome oxidase 1 haplotypes: Two Old World lineages and a New World invasion. Bull. Entomol. Res. 102:573-582.

Canale, M. C., Tomaseto, A. F., Haddad, M. L., Coletta-Filho, H. D., and Lopes, J. R. S. 2017. Latency and persistence of 'Candidatus Liberibacter asiaticus' in its psyllid vector, Diaphorina citri (Hemiptera: Liviidae). Phytopathology 107:264-272.

Chakraborty, N. K., Pandey, P. K., Chatterjee, S. N., and Singh, A. B. 1976. Host preference in Diaphorina citri Kuwayama, vector of greening disease of citrus in India. Indian J. Entomol. 38:196-197.

Coletta-Filho, H. D., Daugherty, M. P., Ferreira, C., and Lopes, J. R. S. 2014. Temporal progression of 'Candidatus Liberibacter asiaticus' infection in citrus and acquisition efficiency by Diaphorina citri. Phytopathology 104:416-421.

Damsteegt, V. D., Postnikova, E. N., Stone, A. L., Kuhlmann, M., Wilson, C., Sechler, A., Schaad, N. W., Brlansky, R. H., and Schneider, W. L. 2010. Murraya paniculata and related species as potential hosts and inoculum reservoirs of 'Candidatus Liberibacter asiaticus', causal agent of huanglongbing. Plant Dis. 94:528-533.

Gottwald, T. R. 2010. Current epidemiological understanding of citrus Huanglongbing. Annu. Rev. Phytopathol. 48:119-139.

Grafton-Cardwell, E. E., Stelinski, L. L., and Stansly, P. A. 2013. Biology and management of Asian citrus psyllid, vector of the Huanglongbing pathogens. Annu. Rev. Entomol. 58:413-432.

Guedes, R. N. C., and Cutler, G. C. 2013. Insecticide-induced hormesis and arthropod pest management. Pest Manag. Sci. 70:690-697.

Halbert, S. E., and Manjunath, K. L. 2004. Asian citrus psyllids (Sternorrhyncha: Psyllidae) and greening disease in citrus: A literature review and assessment of risk in Florida. Fla. Entomol. 87:330-353.

Hall, D. G., Richardson, M. L., Ammar, E.-D., and Halbert, S. E. 2013. Asian citrus psyllid, Diaphorina citri, vector of citrus Huanglongbing disease. Entomol. Exp. Appl. 146:207-223.

Hilf, M. E. 2011. Colonization of citrus seed coats by 'Candidatus Liberibacter asiaticus': Implications for seed transmission of the bacterium. Phytopathology 101:1242-1250.
Hung, T. H., Wu, M. L., and Su, H. J. 2000. Identification of alternative hosts of the fastidious bacterium causing citrus greening disease. J. Phytopathol. 148:321-326.

Inoue, H., Ohnishi, J., Ito, T., Tomimura, K., Miyata, S., Iwanami, T., and Ashihara, W. 2009. Enhanced proliferation and efficient transmission of 'Candidatus Liberibacter asiaticus' by adult Diaphorina citri after acquisition feeding in the nymphal stage. Ann. Appl. Biol. 155:29-36.

Jagoueix, S., Bové, J. M., and Garnier, M. 1994. The phloem-limited bacterium of greening disease of citrus is a member of the $\alpha$ subdivision of the Proteobacteria. Int. J. Syst. Bacteriol. 44:379-386.

Jain, V., Momin, M., and Laddha, K. 2012. Murraya koenigii: An updated review. Int. J. Ayurvedic Herb. Med. 2:607-727.

Killiny, N. 2016. Metabolomic comparative analysis of the phloem sap of curry leaf tree (Bergera koenegii), orange jasmine (Murraya paniculata), and Valencia sweet orange (Citrus sinensis) supports their differential responses to Huanglongbing. Plant Signal. Behav. 11:e1249080.

Koizumi, M., Prommintara, M., and Ohtsu, Y. 1996. Wood apple, Limonia acidissima: a new host for the huanglongbing (greening) vector, Diaphorina citri. Pages 271-275 in: Proceedings of the Thirteenth Conference of the International Organization of Citrus Virologists. J. V. da Graça, P. Moreno, and R. K. Yokomi, eds. IOCV, Riverside, CA.

Kruse, A., Fattah-Hosseini, S., Saha, S., Johnson, R., Warwick, E., Sturgeon, K., Mueller, L., MacCoss, M. J., Shatters, R. G., Jr., and Heck, M. C. 2017. Combining 'omics and microscopy to visualize interactions between the Asian citrus psyllid vector and the Huanglongbing pathogen Candidatus Liberibacter asiaticus in the insect gut. PLoS One 12:e0179531.

Lin, H., Chen, C., Doddapaneni, H., Duan, Y., Civerolo, E. L., Bai, X., and Zhao, X. 2010. A new diagnostic system for ultra-sensitive and specific detection and quantification of Candidatus Liberibacter asiaticus, the bacterium associated with citrus huanglongbing. J. Microbiol. Methods 81:17-25.

Lopes, S. A., Frare, G. F., Bertolini, E., Cambra, M., Fernandes, N. G., Ayres, A. J., Marin, D. R., and Bové, J. M. 2009. Liberibacters associated with citrus huanglongbing in Brazil: 'Candidatus Liberibacter asiaticus' is heat tolerant, 'Ca. L. americanus' is heat sensitive. Plant Dis. 93:257-262.

Lopes, S. A., Frare, G. F., Camargo, L. E. A., Wulff, N. A., Teixeira, D. C., Bassanezi, R. B., Beattie, G. A. C., and Ayres, A. J. 2010. Liberibacters associated with orange jasmine in Brazil: Incidence in urban areas and relatedness to citrus Liberibacters. Plant Pathol. 59:1044-1053.

Lopes, S. A., Luiz, F. Q. B. F., Martins, E. C., Fassini, C. G., Sousa, M. C., Barbosa, J. C., and Beattie, G. A. C. 2013. 'Candidatus Liberibacter asiaticus' titers in citrus and acquisition rates by Diaphorina citri are decreased by higher temperature. Plant Dis. 97:1563-1570.

Lopes, S. A., Luiz, F. Q. B. F., Oliveira, H. T., Arenas, J. C. C., and Raiol, L. L., Jr. 2017. Seasonal variation of 'Candidatus Liberibacter asiaticus' titers in new shoots of citrus in distinct environments. Plant Dis. 101: 583-590.

Murray, M. G., and Thompson, W. F. 1980. Rapid isolation of high molecular weight plant DNA. Nucleic Acids Res. 8:4321-4326.

Nava, D. E., Torres, M. L. G., Rodrigues, M. D. L., Bento, J. M. S., and Parra, J. R. P. 2007. Biology of Diaphorina citri (Hem., Psyllidae) on different hosts and at different temperatures. J. Appl. Entomol. 131:709-715.

Parra, J. R. P., Alves, G. R., Diniz, A. J. F., and Vieira, J. M. 2016. Tamarixia radiata (Hymenoptera: Eulophidae) Diaphorina citri (Hemiptera: Liviidae): Mass rearing and potential use of the parasitoid in Brazil. J. Integr. Pest Manag. 7:1-11.

Pelz-Stelinski, K. S., Brlansky, R. H., Ebert, T. A., and Rogers, M. E. 2010. Transmission parameters for Candidatus Liberibacter asiaticus by Asian citrus psyllid (Hemiptera: Psyllidae). J. Econ. Entomol. 103:1531-1541.

Ramadugu, C., Keremane, M. L., and Halbert, S. E. Ping Duan, Y., Roose, M. L., Stover, E., and Lee, R. F. 2016. Long-term field evaluation reveals Huanglongbing resistance in Citrus relatives. Plant Dis. 100:1858-1869.

Sengoda, V. G., Buchman, J. L., Henne, D. C., Pappu, H. R., and Munyaneza, J. E. 2013. 'Candidatus Liberibacter solanacearum' titer over time in Bactericera cockerelli (Hemiptera: Triozidae) after acquisition from infected potato and tomato plants. J. Econ. Entomol. 106:1964-1972.

Sétamou, M., and Bartels, D. W. 2015. Living on the edges: Spatial niche occupation of Asian citrus psyllid, Diaphorina citri Kuwayama (Hemiptera: Liviidae), in citrus groves. PLoS One 10:e0131917.

Sétamou, M., da Graça, J. V., and Sandoval, J. L., II. 2016. Suitability of native North American Rutaceae to serve as host plants for the Asian citrus psyllid (Hemiptera: Liviidae). J. Appl. Entomol. 140:645-654.

Shelton, A. M., and Badenes-Perez, F. R. 2006. Concepts and applications of trap cropping in pest management. Annu. Rev. Entomol. 51:285-308.

Teck, S. L. C., Fatimah, A., Beattie, A., Heng, R. K. J., and King, W. S. 2011. Influence of host plant species and flush growth stage on the Asian citrus psyllid, Diaphorina citri Kuwayama. Am. J. Agric. Biol. Sci. 6:536-543.

Tiwari, S., Sayed, R. S., Sayed, M. E., and Stelinski, L. L. 2011. Insecticide resistance in field populations of Asian citrus psyllid in Florida. Pest Manag. Sci. 67:1258-1268. 
Walter, A. J., Duan, Y. P., and Hall, D. G. 2012. Titers of ' $\mathrm{Ca}$. Liberibacter asiaticus' in Murraya paniculata and Murraya-reared Diaphorina citri are much lower than in Citrus and Citrus-reared psyllids. HortScience 47: 1449-1452.

Wang, N., and Trivedi, P. 2013. Citrus huanglongbing: a newly relevant disease presents unprecedented challenges. Phytopathology 103: 652-665.

Westbrook, C. J., Hall, D. G., Stover, E., Duan, Y. P., and Lee, R. F. 2011. Colonization of citrus and citrus-related germplasm by Diaphorina citri (Hemiptera: Psyllidae). HortScience 46:997-1005.

Xu, C. F., Xia, Y. H., Li, K. B., and Ke, C. 1988. Further study of the transmission of citrus huanglongbing by a psyllid, Diaphorina citri
Kuwayama. Pages 243-248 In: Proc. 10th Conf. Int. Org. Citrus Virol. L. W. Timmer, S. M. Garnsey, and L. Navarro, eds. IOCV, Valencia, Spain.

Yamamoto, P. T., Alves, G. R., and Beloti, V. H. 2014. Manejo e controle do huanglongbing (HLB) dos cítricos. Invest. Agrar. 16:69-82.

Yamamoto, P. T., and Bassanezi, R. B. 2003. Seletividade de produtos fitossanitários aos inimigos naturais de pragas dos citros. Laranja 24: 353-382.

Yan, H., Zenga, J., and Zhonga, G. 2015. The push-pull strategy for citrus psyllid control. Pest Manag. Sci. 71:893-896.

Zhou, L. J., Gabriel, D. W., Duan, Y. P., Halbert, S. E., and Dixon, W. N. 2007. First report of dodder transmission of huanglongbing from naturally infected Murraya paniculata to citrus. Plant Dis. 91:227. 